\title{
Measuring eudaimonic wellbeing in sport: Validation of the Eudaimonic Wellbeing in Sport Scale
}

\author{
Despina Kouali · Craig Hall · Paige Pope
}

\begin{abstract}
The purpose of this study was to create and validate a sport-specific eudaimonic wellbeing measure (EWBSS; Eudaimonic Wellbeing in Sport Scale) and included three phases. In Phase 1, an initial pool of 19 items was developed and five items were selected by five experts to represent eudaimonic wellbeing in sport (EWBSS). Four hundred athletes (Mage $=24.32$, SD $=6.69$ ) from various individual and team sports participated in Phase 2. Factorial validity and reliability scores were examined using confirmatory factor analysis and alpha coefficient calculations. Results indicated initial evidence for both factorial validity and internal consistency of the EWBSS. In Phase 3, further psychometric testing of the EWBSS with two independent samples (i.e., competitive and recreational athletes) ensued. The findings provided further evidence of sound validity and reliability scores of the EWBSS in competitive athletes. Partial support for the psychometric properties of the EWBSS was provided in recreational athletes. As the validation of an instrument is an ongoing process, more research is needed to further evaluate the validity of the EWBSS.
\end{abstract}

Keywords: eudaimonic wellbeing, validity, motivation, sport

\section{Introduction}

Within the literature, mental wellbeing has been viewed and used interchangeably with various terms such as quality of life, happiness, life satisfaction, vitality, and self-esteem (e.g., Verkooijen, van Hove, \& Dik, 2012). It is widely accepted that wellbeing has been derived from two distinct philosophical traditions: the hedonic view, which focuses on the pursuit of pleasure and pain avoidance, and the eudaimonic view, which focuses on living a meaningful life and self-realization (Ryan \& Deci, 2001). While the hedonic perspective is perceived as to what constitutes a good life and targets specific outcomes, the eudaimonic perspective targets the content of an individual's life together with the processes of a life well-lived (Ryan, Huta, \& Deci, 2008).

Based on the hedonic approach which was initiated from the Greek philosopher Aristippus, wellbeing refers to maximizing pleasure and minimizing pain to achieve human happiness (as a positive subjective state) and is assessed through subjective wellbeing (SWB; Diener, 1984). SWB incorporates both cognitive (i.e., life satisfaction) and affective (i.e., presence of positive affect and

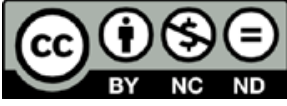

Copyright belongs to the author(s) 
absence of negative affect, summarized as happiness) components and emphasizes individuals' own evaluation whether a good life is being lived (i.e., subjective assessement of life; Diener, 2000).

Initiating from Aristotle's philosophy, the eudaimonic approach emphasizes living well and reaching human potential and defines wellbeing in terms of the level to which an individual is fully functioning (Ryan \& Deci, 2001; Ryan \& Huta, 2009). Based on this approach, wellbeing is operationalized as a set of wellness (i.e., the process of living well) aspects, such as vitality (Ryan \& Deci, 2001; Ryan et al., 2008).

Ryan and Deci (2001), the originators of Self-Determination Theory (SDT; Deci \& Ryan, 1985a) introduced the term of eudaimonic wellbeing (EWB) in a review regarding the two traditions and defined it as a construct that refers to optimal experience and psychological functioning. SDT, as a theory about human motivation and personality, was developed by incorporating aspects from Aristotle's views about eudaimonia (Ryan et al., 2008). Ryan and colleagues, described eudaimonia as living well with specific characteristics: pursuing intrinsic goals, behaving autonomously, being mindful, and satisfying basic psychological needs (i.e., autonomy, competence, and relatedness). Based on this view, EWB is portrayed as an outcome of eudaimonic living. Accordingly, for optimal wellbeing, the fulfillment of the basic psychological needs of autonomy (i.e., sense of volition and choice), competence (i.e., sense of efficacy and mastery), and relatedness (i.e., sense of closeness to others) is required. Specifically, when the psychological needs are completely satisfied, an individual's motivation is self-determined (i.e., the pursuit of an activity by an individual because it is inherently enjoyable), resulting in enhanced wellbeing (e.g., high subjective vitality, growth; Ryan \& Deci, 2000). In contrast, when the needs are thwarted, wellbeing is diminished (e.g., low subjective vitality, impaired functioning; Bartholomew, Ntoumanis, Ryan, \& Thogersen-Ntoumani, 2011).

Although the two approaches namely, hedonia and eudaimonia serve distinct roles in different forms of wellbeing (i.e., SWB and EWB), there is evidence of considerable overlap (e.g., Huta \& Ryan, 2010; Waterman, Schwartz, \& Conti, 2008). For instance, when an individual experiences eudaimonic living, he/she will also experience hedonic pleasure and enjoyment.

SDT researchers have used a diverse set of wellness elements to operationalize EWB (Ryan \& Deci, 2001). For example, the General Causality Orientation Scale (Deci \& Ryan, 1985b) has been used to assess motivational (i.e., autonomous) orientations, while the Aspiration Index (Kasser \& Ryan, 1993) has been used to measure intrinsic goals or aspirations (i.e., relationships, personal growth, and community contributions). Additionally, the Subjective Vitality Scale (Ryan \& Frederick, 1997) has been used to assess the degree to which an individual feels vital, energized, and alive, the Mindful Attention and Awareness Scale (Brown \& Ryan, 2003) to measure awareness of and attention to what is occurring at the moment, and the Basic Psychological Needs Scale (Gagné, 2003) to assess the extent to which a person feels satisfied by the need for autonomy, competence, and relatedness. Employing a diverse set of wellness elements to operationalize EWB can be problematic as it adds burden to participants due to the sheer number of items, and there is potential of overlap in the operationalization of the elements included.

\section{Wellbeing in Sport}

Individual's wellbeing is influenced by different life domains (e.g., work, family). In a review regarding work settings, the specific life context was indicated to be critical for an individual's perceived overall wellbeing (Page \& Vella-Brodrick, 2009). Thus, context-specific wellbeing 
measures targeting specific life domains may provide more detailed and precise information for peoples' wellbeing (Daniels, 2000). Research in sport has underlined that sport engagement is associated with optimal levels of wellbeing and other positive outcomes (e.g., Verner-Filion, Vallerand, Amiot, \& Mocanu, 2017). However, negative experiences in sport may also occur with athletes often facing challenges and obstacles that have a detrimental influence on their physical and psychosocial health, and diminishing their wellbeing (Bartholomew et al., 2011). Several studies examining wellbeing in athletes have either neglected to provide a definition of the construct, used different labels to describe the construct resulting in conceptual ambiguity, or failed to distinguish between general wellbeing and wellbeing specific to the sport context (for a review see Lundqvist, 2011). Given that different factors may influence wellbeing in sport compared to wellbeing in general, assessing sport-specific wellbeing is warranted.

Global measurement tools that have been used to assess SWB in athletes (e.g., Golby \& Wood, 2016; Kipp \& Weiss, 2015) are the Satisfaction with Life Scale (SWLS; Diener, Emmons, Larsen, \& Griffin, 1985) and the Positive and Negative Affect Schedule (PANAS; Watson, Clark, \& Tellegen, 1988), which primarily address hedonic wellbeing. In regards to the eudaimonic approach, the Scales of Psychological Well-Being (SPWB; Ryff, 1989) has been employed with athletes to assess EWB on a global level (e.g., Ferguson, Kowalski, Mack, \& Sabiston, 2014; Lundqvist \& Raglin, 2015). For example, Lundqvist and Raglin (2015) used the 18-item version of SPWB to examine the effects of basic need satisfaction, motivational climate, and personality on elite active orienteers' wellbeing. Additionally, Ferguson, Kowalski, Mack, and Sabiston (2014) explored self-compassion and wellbeing in young women athletes by employing the 84 -item version of the SPWB, and Baltzell and Akhtar (2014) investigated the effectiveness of a mindful meditation training intervention on wellbeing of women soccer players by assessing the 54-item version of the SPWB.

The Subjective Vitality Scale (SVS; Ryan \& Frederick, 1997) is another EWB measurement tool that has been utilized to assess athletes' subjective vitality, a perceived dimension of wellbeing. Although many studies have employed SVS, it does not incorporate all the components of EWB (e.g., Adie, Duda, \& Ntoumanis, 2012; Mack et al., 2011). As a result, the lack of an instrument for measuring athletes' wellbeing in the sport context has been noted as a caveat in the literature (Lundqvist, 2011). Lundqvist (2011) has underlined the importance of developing a sport-specific wellbeing instrument in examining how the competitive environment influences athletes' wellbeing. A sport-specific wellbeing measure might be valuable in better understanding athletes' wellbeing by examining potential relationships with other variables that either enhance or diminish wellbeing.

Considering the gap within the sport literature in measuring wellbeing in sport, the purpose of the present study was to create and validate a sport-specific EWB measure. Our instrument was grounded in SDT and based on the EWB literature (e.g., Ryan et al., 2008).

\section{Phase 1}

The purpose of Phase 1 was to develop a pool of items that might best represent EWB in sport. Recently, Kouali, Hall, and Pope (2018) adapted an existing eudaimonic wellbeing global instrument (i.e., Scales of Psychological Well-Being; Ryff, 1989) for the sport context, and examined the content and factorial validity of this adapted three-factor instrument. Based on their results, they determined that EWB in sport is likely best represented as a unidimensional construct. 


\section{Method}

Participants. A panel of five experts $\left(\mathrm{n}_{\text {males }}=3, \mathrm{n}_{\text {females }}=2\right)$ participated in the study. All participants were academic researchers working at different universities in Canada and who had published articles related to SDT and EWB within the sport context and were currently conducting research on either/both areas.

Procedure. Ethical approval was granted by the institutional research ethics board. The 19 items originally developed by Kouali et al. (2018) served as the basis for the new sport-specific EWB measure. Two investigators re-assessed the technical qualities (i.e., length, readability, and clarity) and the item-content validity (i.e., the extent to which the content of each item is relevant to measure the construct; Lynn, 1986) of these items. After finalizing the items by making alterations (i.e., rewording and deleting phrases from items), the investigators contacted five experts via email to determine their willingness and availability to participate in the study. All experts agreed to provide their feedback on the set of items. Each expert first read the definition of the construct and then selected the items that best represent EWB in sport. A comment box was also provided so the experts could explain any of their answers or make any comments. The panel of experts sent back their answers in a document that was attached in the email invitation.

\section{Results and Discussion}

Based on the percentage of consensus among experts' responses, each item was retained or removed from the item list. Of the 19 items, $80 \%$ agreement was found for five items, $60 \%$ for four items, $40 \%$ for five items, and $20 \%$ for three items. Also, two items were not selected by any expert. Generally, there are basic guidelines that researchers should follow regarding the items that identify a construct (DeVellis, 2012). DeVellis suggested that the initial pool of items should be three or four times larger than the number of items that will be included in the final scale. Each item should be simple, parsimonious, clearly phrased, and concise, while double or triple barreled, negatively worded or reversed score items should be avoided (Hinkin, Tracey, \& Enz, 1997). In terms of the appropriate number of items that should represent a scale, Costello and Osborne (2005) suggested that five or more items should indicate a solid factor, whereas Hinkin et al. recommended four to six items for the development of a quality scale. Furthermore, when a scale is short it helps to reduce the burden on respondents compared to a longer scale (DeVellis, 2012). Therefore, the five items with the highest level of agreement (80\%) were retained to represent EWB in sport (Table 1) termed the Eudaimonic Wellbeing in Sport Scale (EWBSS) and to be further examined in the next phase (Phase 2).

\section{Phase 2}

The purpose of Phase 2 was to test the EWBSS by examining the factorial validity and reliability of the instrument.

\section{Method}

Participants. Four hundred $\left(\mathrm{n}_{\text {males }}=299 ; \mathrm{n}_{\text {females }}=101\right)$ competitive athletes (Mage $=24.32, \mathrm{SD}$ $=6.69$ ) from 25 different team and individual sports ( $47 \%$ indicated engaging in soccer) participated in the study. Athletes played at varsity $(n=34)$, regional $(n=20)$, provincial $(n=293)$, national $(n=$ $23)$, and international $(n=20)$ levels. On average, the athletes practiced 11.54 hours per week $(S D=$ 
4.07) and had been participating in their sport for 12.16 years $(S D=5.71)$. Participants reported that they were at the pre-season stage $(n=269)$, early season stage $(n=46)$, middle season stage $(n=22)$, late season stage $(n=12)$, and off-season stage $(n=51)$, while $97 \%$ indicated currently having a coach. In terms of athletes' ethnicity, the majority described themselves as Caucasian $(n=364)$.

Measures. Demographics. The demographic questionnaire included information about age, gender, ethnicity, major sport, years of participation in respective sport, hours practiced per week, competitive level, stage of competitive season of major sport, and if they currently had a coach or not.

Table 1

Descriptive Statistics, Factor Loadings, and Error Terms of the Eudaimonic Well-Being in Sport Scale Items

$\begin{array}{lllll}M & S D & \text { Skewness } & \text { Kurtosis } & \text { ER }\end{array}$

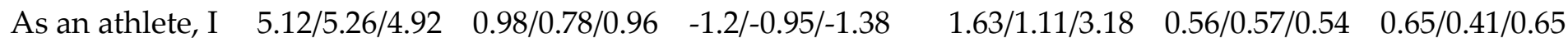

feel that I

continue to

learn more

about myself.

I have a sense $\quad 4.9 / 5.19 / 4.92 \quad 1 / 0.87 / 0.95 \quad-1.25 /-1.06 /-1.29 \quad 2.4 / 1.32 / 2.87 \quad 0.69 / 0.63 / 0.56 \quad 0.53 / 0.45 / 0.62$

of direction in

sport.

My goals in $\quad 5.07 / 5.17 / 5.16 \quad 0.97 / 0.88 / 0.84 \quad-1.18 /-1.93 /-1.33 \quad 1.71 / 1.49 / 2.83 \quad 0.71 / 0.74 / 0.83 \quad 0.47 / 0.34 / 0.22$

sport have

been a source

of satisfaction.

In general, I $\quad 5 / 5.16 / 5.07 \quad 0.96 / 0.80 / 0.80 \quad-1.9 /-0.98 /-0.70 \quad 1.59 / 1.39 / 0.83 \quad 0.53 / 0.81 / 0.91 \quad 0.66 / 0.22 / 0.11$

feel positive

about myself

as an athlete.

I like most $\quad 5.02 / 5.17 / 5.04 \quad 1.02 / 0.90 / 0.90 \quad-1.36 /-1.68 /-1.37 \quad 2.42 / 4.34 / 3.67 \quad 0.53 / 0.66 / .051 \quad 0.75 / 0.46 / 0.60$

aspects of

myself as an

athlete.

Note. $M=$ Mean; $S D=$ Standard Deviation; $F L=$ Factor Loading; $E R=$ Error term. Values presented before the first slash (/) refer to athletes' scores on the corresponding statistic in Phase 2 . The values presented before the 
second slash represent competitive athletes' scores from Phase 3, whereas the values presented after the second slash represent recreational athletes' scores also from Phase 3.

Eudaimonic wellbeing. The Eudaimonic Wellbeing in Sport Scale (EWBSS) was used to measure athletes' wellbeing. The EWBSS consists of five items (e.g., "As an athlete, I feel that I continue to learn more about myself"; see Table 1). Athletes were asked to circle the number that best describes their present agreement or disagreement with each item using a six-point Likert scale ranging from 1 (strongly disagree) to 6 (strongly agree).

Procedure. Once approval was granted by the institutional research ethics board, one of the investigators identified coaches' contact information via official websites of varsity teams and contacted them via email in order to receive permission to contact their athletes. After receiving permission from coaches to approach their athletes, the investigator contacted the athletes before or after their practice, explaining to them briefly the purpose of the study and providing them a letter of information. The athletes who agreed to participate, completed the corresponding paper and pencil (without the presence of the coaches) or online questionnaire. An email script with the questionnaire link was sent to the participants that wished to complete the survey online. Completion of the questionnaire indicated athletes' consent to participate.

Data analysis. After screening the data for outliers, missing and incomplete data, the factorial validity of the EWBSS was examined with confirmatory factor analysis (CFA) using AMOS 24.0 software (Arbuckle, 2016). The goodness-of-fit of the hypothesized model was tested using four indices suggested by Kline (2005): the chisquare statistic $(\chi 2)$, the comparative fit index (CFI), the root mean square error of approximation (RMSEA), and the standardized root mean residual (SRMR). Hu and Bentler (1999) for CFI recommended that values above 95 indicate an excellent fit, while more recently Marsh, Hau, and Wen (2004) suggested that values greater than .90 indicate a good fit. Additionally, RMSEA values equal or less than .06 are desired, while SRMR values less than .08 denote acceptable fit (Hu \& Bentler, 1999). Cronbach alpha coefficient was also calculated for the EWBSS.

\section{Results and Discussion}

The descriptive statistics of the final five items are presented in Table 1, including the mean, standard deviation, skewness, and kurtosis scores. Additionally, the scale showed acceptable internal consistency $(\alpha=.74)$. Moreover, the factor loading scores and error term scores for the final five items are also provided in Table 1 . The CFA model with the five items representing the EWBSS revealed an excellent fit to the data $(\chi 2(5)=7.55, p=.18$; $\mathrm{CFI}=.99 ; \mathrm{RMSEA}=.04 ; \mathrm{SRMR}=.02$ ). Therefore, initial support for the factorial validity and reliability of the EWBSS was provided when it was tested on a large sample with competitive level athletes. However, further validation of the five items was needed.

\section{Phase 3}

The purpose of this phase was to further test the psychometric properties of the EWBSS. Accordingly, factorial validity, nomological validity, convergent validity, and reliability of EWBSS were evaluated with two independent samples, competitive athletes and recreational athletes. While it is widely accepted that physical activity and sport participation is associated with psychological benefits including enhanced wellbeing (e.g., Adie et al., 2012), there is evidence showing that there are differences in wellbeing between the various levels of the competitors. For example, Chatzisarantis and Hagger (2007) examined the effect of recreational and competitive sport participation on the wellbeing of UK athletes and found that recreational athletes reported higher levels of both SWB and EWB compared with competitive athletes. In another study with Australian women (Eime, Harvey, Brown, \& Payne, 2010), club sport participants demonstrated higher levels of SWB than participants 
engaging in gym activities or walking. While the EWBSS was designed to be suitable for any sport level, in the present phase competitive athletes and recreational athletes were examined separately to determine if the EWBSS was equally appropriate for both groups.

The nomological and convergent validity were examined in relation to constructs of SDT. Following Lonsdale, Hodge, and Rose's (2008) approach providing evidence regarding the nomological validity of the Behavioral Regulation in Sport Questionnaire (BRSQ) with elite and non-elite athletes, nomological validity was measured in relation to the six types of motivation based on SDT (Ryan \& Deci, 2000). The SDT framework postulates that different types of motivation lie on a continuum relative to self-determination and internalization (Ryan \& Deci, 2000). Specifically, intrinsic motivation (participation in an activity by an individual for its own sake), integrated regulation (engagement in a behavior because it is an important part of individual's identity), and identified regulation (engagement in a behavior because it is highly valued) are characterized as autonomous types of motivation. Introjected regulation (engaging in an activity in order to avoid guilt or anxiety or to maintain the feeling of worth), external regulation (the desire to obtain an award, social recognition, or avoid punishment) are characterized as controlled types of motivation, and amotivation is a lack of intention to engage in a behavior (Ryan \& Deci, 2000). Accordingly, SDT posits that autonomous types of motivation are positively associated with EWB, whereas controlled types of motivation and amotivation are negatively associated with EWB (Ryan \& Deci, 2000). To evaluate convergent validity, the association between EWBSS and SVS was tested. SVS has been broadly used in sport psychology studies (e.g., Mack et al., 2011) to measure subjective vitality as a dynamic aspect of EWB, as well as an outcome of eudaimonic living (Ryan et al., 2008).

It was hypothesized that a) evidence of the factorial validity and reliability of EWBSS would be provided, b) autonomous types of motivation (i.e., intrinsic motivation, integrated regulation, and identified regulation) would be positively related to EWBSS, while controlled types of motivation (i.e., introjected regulation and external regulation) and amotivation would be negatively related to EWBSS (nomological validity), and c) EWBSS would be strongly correlated with SVS (convergent validity).

\section{Method}

Participants. The two samples consisted of 139 (nmales $=46$; $\left.n_{\text {females }}=93\right)$ competitive athletes $($ Mage $=19.76$, $\mathrm{SD}=1.44)$ from 21 individual and team sports (35.3\% indicated engaging in track and field), and 104 (nmales $=48$; $\left.n_{\text {females }}=56\right)$ recreational athletes (Mage $\left.=20.46, \mathrm{SD}=2.43\right)$ from 22 individual and team sports $(25 \%$ indicated playing soccer). The majority of the competitive athletes played at varsity level $(n=108)$ and were at the early season stage $(n=79)$, whereas the majority of recreational athletes were at the off-season stage $(n=40)$. On average, the competitive athletes practiced 12.06 hours $(\mathrm{SD}=4.89)$ and had been participating in their sport for 9.64 years $(S D=4.91)$. The recreational athletes practiced less hours per week $(M=5.13, S D=3.29)$ and reported that they had been participating in their sport on average for 9.74 years $(\mathrm{SD}=4.56)$. Most of the participants from both samples described themselves as Caucasian ( $n_{\text {competitive }}=123 ; n_{\text {recreational }}=70$ ). Additionally, $97.5 \%$ of competitive athletes and only $32.7 \%$ of recreational athletes indicated currently having a coach/instructor.

Measures. Demographics. The same demographic questionnaire used in Phase 2 was employed.

Eudaimonic wellbeing. The EWBSS was used to measure athletes' wellbeing as in Phase 2.

Motivation. The Behavioral Regulation in Sport Questionnaire (BRSQ; Lonsdale et al., 2008) was used to assess athletes' motivation by indicating the reasons they participate in their sport and responding on a sevenpoint Likert scale from 1 (not at all true) to 7 (very true). The 24-item questionnaire includes six subscales: intrinsic motivation (e.g., "because it's fun”), integrated regulation (e.g., "because it's an opportunity to just be who I am”), identified regulation (e.g., "because I value the benefits of my sport"), introjected regulation (e.g., "because I 
would feel guilty if I quit"), external regulation (e.g., "in order to satisfy people who want me to play"), and amotivation (e.g., "but I question why I continue"). Supportive evidence regarding the reliability and factorial validity of the BRSQ has been reported in four studies conducted by Lonsdale and colleagues (2008) and the BRSQ has been effectively employed in a number of studies (e.g., Lonsdale \& Hodge, 2011).

Subjective vitality. The six-item version of Subjective Vitality Scale (SVS; Ryan \& Frederick, 1997) was used to assess the degree to which participants feel vital, energized, and alive in their life as athletes. The items (e.g., "I feel alive and vital”) are answered on a seven-point Likert scale ranging from 1 (not at all true) to 7 (very true). The reliability and validity of the scale has been supported by previous research (e.g., Bostic, Rubio, \& Hood, 2000).

Procedure. Approval for the study was granted by the institutional research ethics board. After receiving permission from instructors teaching university kinesiology courses, one of the investigators contacted students (at the end of the class) explaining to them briefly the purpose of the study. A letter of information and the questionnaire were then administered to them using a paper and pencil format. By completing the questionnaire implicit consent was obtained to participate in the study. The instructors were not present during class recruitment and data collection.

Data analysis. Descriptive statistics and Cronbach alpha coefficient scores of both samples' responses were calculated for all the examined variables. Similar to Phase 2, the factorial validity of the EWBSS scores for each sample was examined with CFA, and the goodness-of-fit of the hypothesized model was tested using the same indices ( $\chi 2, \mathrm{CFI}, \mathrm{RMSEA}$, and SRMR). Bivariate correlations (Pearson correlation) were also computed to test patterns of association between the constructs.

\section{Results}

Descriptive statistics, scale reliabilities, and CFA. The descriptive statistics and Cronbach alpha coefficient scores of competitive and recreational athletes' responses for all variables are presented in Table 2 and Table 3. On average, both competitive and recreational athletes scored above the midpoint for the EWBSS, SVS, and autonomous types of motivation subscales. Participants' responses from both samples were on average below the midpoint for the non-autonomous types of motivation subscales. All the examined variables had acceptable levels of internal consistency with alphas ranging from .76 to .90 with the exception of the identified regulation subscale for the recreational athletes which indicated a poor level of reliability $(\alpha=.59)$. While the results for this variable are reported, the findings that include identified regulation for recreational athletes must be interpreted with caution.

Similar to Phase 2, the mean, standard deviation, skewness, kurtosis, factor loading, and error term scores for all items are presented in Table 1. For the sample with competitive athletes, fit index scores reflected adequate fit with the exception of one index (RMSEA) which did not reach the cutoff criterion $(\chi 2(5)=27.21, \mathrm{p}<.001$; CFI $=.90 ; \mathrm{RMSEA}=.18$; SRMR $=.06)$. For the sample with recreational athletes, the CFA model representing the EWBSS revealed a much poorer fit to the data $(\chi 2(5)=27.28, \mathrm{p}<.001 ; \mathrm{CFI}=.88$; RMSEA $=.21 ; \mathrm{SRMR}=.08)$. 
Table 2

Descriptive Statistics, Reliability Coefficients, and Bivariate Correlations between Study Variables for Competitive Athletes from

Phase 3

\begin{tabular}{|c|c|c|c|c|c|c|c|c|c|c|c|}
\hline Variables & $M$ & $S D$ & $\begin{array}{l}\text { Scale } \\
\text { Range }\end{array}$ & $\alpha$ & 1 & 2 & 3 & 4 & 5 & 6 & 7 \\
\hline 1. Intrinsic Motivation & 6.13 & 0.92 & $1-7$ & .90 & - & & & & & & \\
\hline 2. Integrated Regulation & 5.60 & 1.08 & $1-7$ & .81 & $.59 * *$ & - & & & & & \\
\hline 3. Identified Regulation & 5.94 & 0.90 & $1-7$ & .76 & $.49 * *$ & $.61^{* *}$ & - & & & & \\
\hline 4. Introjected Regulation & 3.43 & 1.64 & $1-7$ & .88 & $-.25 * *$ & -.04 & -.10 & - & & & \\
\hline う. External Regulation & 2.45 & 1.32 & $1-7$ & .86 & $-.23 * *$ & -.10 & -.12 & $.60 * *$ & - & & \\
\hline 5. Amotivation & 2.35 & 1.28 & $1-7$ & .86 & $-.50 * *$ & $-.30 * *$ & $-.26 * *$ & $.54^{* *}$ & $.56^{* *}$ & - & \\
\hline 7. Subjective Vitality & 4.85 & 1.05 & $1-7$ & .85 & $.44 * *$ & $.45^{* *}$ & $.32 * *$ & -.15 & -.08 & $-.23 * *$ & - \\
\hline 3. Eudaimonic Well-Being & 5.19 & 0.64 & $1-6$ & .81 & $.49 * *$ & $.45^{* *}$ & $.45^{* *}$ & $-.34 * *$ & $-.31 * *$ & $-.44 * *$ & $.59 * *$ \\
\hline
\end{tabular}

Note. $M=$ Mean; $S D=$ Standard Deviation; $\alpha=$ Cronbach alpha coefficient; ** $p<.01$.

Table 3

Descriptive Statistics, Reliability Coefficients, and Bivariate Correlations between Study Variables for Recreational Athletes from

Phase 3

\begin{tabular}{|c|c|c|c|c|c|c|c|c|c|c|c|c|}
\hline Variables & $M$ & $S D$ & $\begin{array}{l}\text { Scale } \\
\text { Range }\end{array}$ & $\alpha$ & 1 & 2 & 3 & 4 & 5 & 6 & 7 & 8 \\
\hline 1.Intrinsic Motivation & 6.50 & 0.65 & $1-7$ & .78 & - & & & & & & & \\
\hline 2. Integrated Regulation & 5.33 & 1.10 & $1-7$ & .80 & $.46^{* *}$ & - & & & & & & \\
\hline 3. Identified Regulation & 5.72 & 0.85 & $1-7$ & .59 & $.36^{* *}$ & $.54 * *$ & - & & & & & \\
\hline 4. Introjected Regulation & 2.81 & 1.35 & $1-7$ & .78 & $-.27 * *$ & -.10 & .07 & - & & & & \\
\hline 5. External Regulation & 2.16 & 1.11 & $1-7$ & .82 & $-.36 * *$ & -.00 & .07 & $.57 * *$ & - & & & \\
\hline 6. Amotivation & 1.91 & 1.00 & $1-7$ & .83 & $-.52 * *$ & -.12 & -.09 & $.65^{* *}$ & $.65 * *$ & - & & \\
\hline 7. Subjective Vitality & 5.06 & 0.90 & $1-7$ & .80 & $.27 * *$ & $.28 * *$ & $.42 * *$ & -.13 & -.07 & -.16 & - & \\
\hline 8. Eudaimonic Well-Being & 5.02 & 0.67 & $1-6$ & .80 & $.49 * *$ & $.59 * *$ & $.52 * *$ & -.14 & -.15 & $-.31 * *$ & $.46^{* *}$ & - \\
\hline
\end{tabular}

Note. $M=$ Mean; $S D=$ Standard Deviation; $\alpha=$ Cronbach alpha coefficient; $* * p<.01$.

Nomological and convergent validity. The bivariate correlations between all the variables are also presented in Table 2 and Table 3. Competitive and recreational athletes' autonomous types of motivation were positively associated with EWB. Negative relationships were found between the controlled types of motivation (including amotivation) and EWB in competitive athletes, whereas only amotivation was found to be negatively associated with EWB in recreational athletes. Positive correlations were found between EWBSS scores and SVS scores of both competitive and recreational athletes.

\section{Discussion}

The results from this phase provided further evidence supporting the factorial validity of the EWBSS, but primarily for competitive athletes. Support was provided for the nomological validity of the EWBSS with competitive athletes, but only partial support for nomological validity was found with recreational athletes as 
introjected regulation and external regulation were non-significantly correlated with the EWBSS. As was expected, EWB as assessed by the EWBSS was significantly related to subjective vitality, which provided support for the convergent validity of the EWBSS with both athlete samples. The findings from this phase also provided support for the reliability of the EWBSS with both competitive and recreational athletes.

\section{General Discussion}

Research in sport has examined athletes' EWB demonstrating positive relationships between sport participation, autonomous motivation, and wellbeing (e.g., Adie et al., 2012). However, a notable limitation of this research is the absence of a sport specific measure of EWB. The first purpose of this research was to create an initial pool of items that capture wellbeing based on the eudaimonic perspective. Grounded in SDT, the initial 19 items were reduced to five items based on the feedback provided by five expert judges.

The second purpose of the present research was to examine the factorial validity and reliability of the fiveitem EWBSS. Thus, the new instrument was tested on a large sample with high level competitive athletes. The findings provided initial support for the factorial validity and reliability of the EWBSS. Given the EWBSS was a new instrument, further validation of the five-item structure with other samples was imperative. Accordingly, the factorial validity and reliability of the instrument were re-examined with a sample of competitive athletes and a sample of recreational athletes, and further psychometric testing of nomological and convergent validity was conducted. Supportive evidence concerning the different types of validity and internal consistency of the EWBSS was found in the sample of competitive athletes, while only partial support for the psychometric properties of EWBSS was found with recreational athletes.

In an attempt to understand why the EWBSS was more applicable to competitive athletes than recreational athletes, we asked participants from both samples to tell us in their opinion how applicable they felt that the EWBSS items are for themselves and their lives as athletes. Pelliccia et al. (2005) defined competitive athletes as individuals who participate in systematic training on a regular basis and compete in official sporting events, whereas recreational athletes were described as individuals who engage in sport activities without requiring consistent training. While the competitive athletes thought all items of the instrument were applicable to them, the recreational athletes commented that items 2 and 5 are not really suitable for their level of play. It seems that for the individuals that participate in sport primarily to experience enjoyment (i.e., intrinsic motivation), which is characteristic of recreational athletes, they lack specific goals or direction in sport (item 2) or they have goals that are not directly related to their sport (e.g., to be physically fit, to have meaningful relationships; Chatzisarantis \& Hagger, 2007). Furthermore, as recreational athletes do not have a very strong athletic identity (Lamont-Mills \& Christensen, 2006), aspects of themselves are not identified by their sport (item 5). Therefore, based on the nature of the items, EWBSS appears to be more suitable for competitive athletes.

Our research is not without limitations. We only classified athletes as competitive and recreational. In addition to confirming the differences between competitive and recreational athletes in responding to EWBSS, it would be worthwhile to examine the instrument with other levels of competitive athletes (e.g., masters athletes, high school athletes) in order to determine if this instrument is appropriate for all competitive athletes. Additionally, it would be worthwhile for scholars to compare various samples of athletes (e.g., individual versus team sports, different age groups, male versus female athletes) and determine if they exhibit differences in their wellbeing levels. In this research we only considered the nomological and convergent validity of the EWBSS. Given the validation of an instrument is an ongoing process, more research is needed to examine other types of validity such as discriminant, predictive, and concurrent validity. The test-retest reliability of the instrument also needs to be investigated. 
The EWBSS was developed to represent eudaimonic aspects as indicators of optimal functioning and experience in the sport context. However, recently Ryan and Deci (2017) used the term of thriving to describe full functioning by including two main components: a eudaimonic component (i.e., vitality) and a performance component (i.e., exercise of one's human capacities). Similarly, Brown and colleagues (Brown, Arnold, Reid, \& Roberts, 2018; Brown, Arnold, Standage, \& Fletcher, 2017) investigated thriving in sport and suggested that the experience of thriving incorporates some similar characteristics with the experience of EWB and eudaimonic living (which align with SDT) combined with aspects of athletic performance. More specifically, thriving was described as the experience of both a high-level of wellbeing and a perceived high-level of performance following adversity or successful events. Therefore, future research should consider incorporating the dimension of subjective performance together with the EWBSS in order to capture a more holistic view of being fully functioning in sport, instead of using separate measures to assess wellbeing and performance (Brown et al., 2017).

Previous studies have assessed EWB in sport by employing a global measure of wellbeing (e.g., SPWB) or by employing multiple measures to assess various aspects of EWB (e.g., subjective vitality, awareness). Our attempt to provide a measure that is relatively short and easy to administer, while still encompassing the main components of EWB in sport, should encourage researchers to use the new instrument in order to further examine and understand athletes' wellbeing. Researchers in future studies should investigate whether athletes' wellbeing varies with athletes' characteristics (e.g., age, gender, sport, stage of the competitive season, and cultural background). Future research should also examine the relationship between the EWBSS and other constructs of SDT (e.g., basic psychological needs) to see if the findings are consistent with tenets of SDT.

The findings from the present study have implications for coaches and practitioners working with athletes. As the EWBSS is a relatively straight forward instrument that reduces the burden on athletes, it can be easily administered multiple times throughout the season. Therefore, practitioners can design interventions that may enhance athletes' wellbeing and effectively assess these interventions employing the EWBSS.

\section{Authors}

Despina Kouali

The University of Western Ontario

dkouali@uwo.ca

Craig Hall

The University of Western Ontario

Paige Pope

University of Lethbridge

\section{Publishing Timeline}

Received 3 October 2018

Accepted 14 October 2019

Published 1 February 2020 


\section{References}

Adie, J. W., Duda, J. L., \& Ntoumanis, N. (2012). Perceived coach-autonomy support, basic need satisfaction and the welland ill-being of elite youth soccer players: A longitudinal investigation. Psychology of Sport and Exercise, 13(1), 51-59.

Arbuckle, J. L. (2016). Amos (Version 24.0) [Computer Program]. Chicago: IBM SPSS.

Baltzell, A., \& Akhtar, V. L. (2014). Mindfulness meditation training for sport (MMTS) intervention: Impact of MMTS with division I female athletes. The Journal of Happiness and Well-Being, 2(2), 160-173.

Bartholomew, K. J., Ntoumanis, N., Ryan, R. M., \& Thøgersen-Ntoumani, C. (2011). Psychological need thwarting in the sport context: Assessing the darker side of athletic experience. Journal of Sport and Exercise Psychology, 33(1), 75-102.

Bostic, T. J., Rubio, D. M., \& Hood, M. (2000). A validation of the subjective vitality scale using structural equation modeling. Social Indicators Research, 52, 313-324.

Brown, D. J., Arnold, R., Reid, T., \& Roberts, G. (2018). A qualitative exploration of thriving in elite sport. Journal of Applied Sport Psychology, 30(2), 129-149.

Brown, D. J., Arnold, R., Standage, M., \& Fletcher, D. (2017). Thriving on pressure: A factor mixture analysis of sport performers' responses to competitive encounters. Journal of Sport and Exercise Psychology, 39(6), 423-437.

Brown, K. W., \& Ryan, R. M. (2003). The benefits of being present: mindfulness and its role in psychological well-being. Journal of Personality and Social Psychology, 84(4), 822-848.

Chatzisarantis, N. L., \& Hagger, M. S. (2007). The moral worth of sport reconsidered: Contributions of recreational sport and competitive sport to life aspirations and psychological well-being. Journal of Sports Sciences, 25(9), 1047-1056.

Costello, A. B., \& Osborne, J. W. (2005). Best practices in exploratory factor analysis: Four recommendations for getting the most from your analysis. Practical Assessment, Research \& Evaluation, 10(7), 1-9.

Daniels, K. (2000). Measures of five aspects of affective well-being at work. Human Relations, 53(2), 275-294.

Deci, E. L., \& Ryan, R. M. (1985a). Intrinsic motivation and self-determination in human behavior. New York, NY: Plenum.

Deci, E. L., \& Ryan, R. M. (1985b). The general causality orientations scale: Self-determination in personality. Journal of Research in Personality, 19, 109-134.

DeVellis, R. F. (2012). Scale development: Theory and applications (3rd ed.). Thousand Oaks: Sage Publications.

Diener, E. (1984). Subjective well-being. Psychological Bulletin, 95, 524-575.

Diener, E. (2000). Subjective well-being: The science of happiness and a proposal for a national index. American Psychologist, 55(1), 34.

Diener, E., Emmons, R.A., Larsen, R.J., \& Griffin, S. (1985). The satisfaction with life scale. Journal of Personality Assessment, $49,71-75$.

Eime, R. M., Harvey, J. T., Brown, W. J., \& Payne, W. R. (2010). Does sports club participation contribute to health-related quality of life? Medicine \& Science in Sports E Exercise, 42(5), 1022-1028.

Ferguson, L. J., Kowalski, K. C., Mack, D. E., \& Sabiston, C. M. (2014). Exploring self-compassion and eudaimonic wellbeing in young women athletes. Journal of Sport and Exercise Psychology, 36, 203-2016.

Gagné, M. (2003). The role of autonomy support and autonomy orientation in prosocial behavior engagement. Motivation and Emotion, 27(3), 199-223.

Golby, J., \& Wood, P. (2016). The effects of psychological skills training on mental toughness and psychological well-being of student-athletes. Psychology, 7(6), 901-913.

Hinkin, T. R., Tracey, J. B., \& Enz, C. A. (1997). Scale construction: Developing reliable and valid measurement instruments. Journal of Hospitality \& Tourism Research, 21(1), 100-120.

Hu, L. T., \& Bentler, P. M. (1999). Cutoff criteria for fit indexes in covariance structure analysis: Conventional criteria versus new alternatives. Structural Equation Modeling, 6(1), 1-55.

Huta, V., \& Ryan, R. M. (2010). Pursuing pleasure or virtue: The differential and overlapping well-being benefits of hedonic and eudaimonic motives. Journal of Happiness Studies, 11(6), 735-762.

Kasser, T., \& Ryan, R. M. (1993). A dark side of the American dream: Correlates of financial success as a central life aspiration. Journal of Personality and Social Psychology, 65, 410-422. 
Kipp, L. E., \& Weiss, M. R. (2015). Social predictors of psychological need satisfaction and well-being among female adolescent gymnasts: A longitudinal analysis. Sport, Exercise, and Performance Psychology, 4(3), 153-169.

Kline, R. B. (2005). Principles and practice of structural equation modeling (2nd ed.). New York, NY: Guilford Press.

Kouali, D., Hall, C., \& Pope, P. (2018). Examining an adapted version of Ryff's Scales of Psychological Well-Being in Sport. Baltic Journal of Health and Physical Activity, 10(4), 213-225.

Lamont-Mills, A., \& Christensen, S. A. (2006). Athletic identity and its relationship to sport participation levels. Journal of Science and Medicine in Sport, 9(6), 472-478.

Lonsdale, C., \& Hodge, K. (2011). Temporal ordering of motivational quality and athlete burnout in elite sport. Medicine $\mathcal{E}$ Science in Sports \& Exercise, 43(5), 913-921.

Lonsdale, C., Hodge, K., \& Rose, E. A. (2008). The Behavioral Regulation in Sport Questionnaire (BRSQ): Instrument development and initial validity evidence. Journal of Sport and Exercise Psychology, 30(3), 323-355.

Lundqvist, C. (2011). Well-being in competitive sports-the feel-good factor? A review of conceptual consideration of wellbeing. International Review of Sport and Exercise Psychology, 4, 109-127. doi:10.1080/1750984X.2011.584067

Lundqvist, C., \& Raglin, J. S. (2015). The relationship of basic need satisfaction, motivational climate and personality to well-being and stress patterns among elite athletes: An explorative study. Motivation and Emotion, 39(2), 237-246.

Lynn, M. R. (1986). Determination and quantification of content validity. Nursing research, 35(6), 382-386.

Mack, D. E., Wilson, P. M., Oster, K. G., Kowalski, K. C., Crocker, P. R., \& Sylvester, B. D. (2011). Well-being in volleyball players: Examining the contributions of independent and balanced psychological need satisfaction. Psychology of Sport and Exercise, 12(5), 533-539.

Marsh, H. W., Hau, K. T., \& Wen, Z. (2004). In search of golden rules: Comment on hypothesis-testing approaches to setting cutoff values for fit indexes and dangers in overgeneralizing Hu and Bentler's (1999) findings. Structural equation modeling, 11(3), 320-341.

Page, K. M., \& Vella-Brodrick, D. A. (2009). The 'what','why' and 'how' of employee well-being: A new model. Social Indicators Research, 90(3), 441-458.

Pelliccia, A., Fagard, R., Bjørnstad, H. H., Anastassakis, A., Arbustini, E., Assanelli, D., ... \& Delise, P. (2005).

Recommendations for competitive sports participation in athletes with cardiovascular disease: A consensus document from the study group of sports cardiology of the working group of cardiac rehabilitation and exercise physiology and the working group of myocardial and pericardial diseases of the European Society of Cardiology. European Heart Journal, 26(14), 1422-1445.

Ryan, R. M., \& Deci, E. L. (2000). Self-determination theory and the facilitation of intrinsic motivation, social development, and well-being. American Psychologist, 55(1), 68-78.

Ryan, R. M., \& Deci, E. L. (2001). On happiness and human potentials: A review of research on hedonic and eudaimonic well-being. Annual Review of Psychology, 52, 141-166. doi:10.1146/annurev.psych.52.1.141.

Ryan, R. M., \& Deci, E. L. (2017). Self-determination theory: Basic psychological needs in motivation, development, and wellness. New York, NY: Guilford Press.

Ryan, R. M., \& Frederick, C. M. (1997). On energy, personality and health: Subjective vitality as a dynamic reflection of well-being. Journal of Personality, 65, 529-565.

Ryan, R. M., \& Huta, V. (2009). Wellness as healthy functioning or wellness as happiness: The importance of eudaimonic thinking (response to the Kashdan et al. and Waterman discussion). The Journal of Positive Psychology, 4(3), $202-204$.

Ryan, R. M., Huta, V., \& Deci, E. L. (2008). Living well: A self-determination theory perspective on eudaimonia. Journal of Happiness Studies, 9, 139-170. doi:10.1007/s10902-006-9023-4

Ryff, C. D. (1989). Happiness is everything, or is it? Explorations on the meaning of psychological well-being. Journal of Personality and Social Psychology, 57, 1069-1081. doi:10.1037/0022-3514.57.6.1069

Verkooijen, K. T., van Hove, P., \& Dik, G. (2012). Athletic identity and well-being among young talented athletes who live at a Dutch elite sport center. Journal of Applied Sport Psychology, 24(1), 106-113.

Verner-Filion, J., Vallerand, R. J., Amiot, C. E., \& Mocanu, I. (2017). The two roads from passion to sport performance and psychological well-being: The mediating role of need satisfaction, deliberate practice, and achievement goals. Psychology of Sport and Exercise, 30, 19-29. 
Waterman, A. S., Schwartz, S. J., \& Conti, R. (2008). The implications of two conceptions of happiness (hedonic enjoyment and eudaimonia) for the understanding of intrinsic motivation. Journal of Happiness Studies, 9(1), 41-79.

Watson, D., Clark, L. A., \& Tellegen, A. (1988). Development and validation of brief measures of positive and negative affect: The PANAS scales. Journal of Personality and Social Psychology, 54(6), 1063-1070. 